Tatiana Dizhbite*, Lilija Jashina, Galina Dobele, Anna Andersone, Dmitry Evtuguin, Oskar Bikovens and Galina Telysheva

\title{
Polyoxometalate (POM)-aided modification of lignin from wheat straw biorefinery
}

\begin{abstract}
The oxidative modification of Biolignin (BL) has been investigated to make it more suitable as an adsorbent for transition/heavy metals. BL is a by-product of a wheat straw organosolv process for the production of pulp, ethanol, and pentoses (CIMV S.A. pilot plant, Levallois Perret, France). It was subjected to oxidation by a polyoxometalate (POM) $\mathrm{H}_{3}\left[\mathrm{PMo}_{12} \mathrm{O}_{40}\right]$, aiming at the increment of oxygen-containing adsorption-active sites. The POM oxidation of BL was performed under moderate conditions ( 1 bar, $60-90^{\circ} \mathrm{C}$, and $200^{\circ} \mathrm{C}$ ) with the co-oxidants $\mathrm{O}_{2}$ or $\mathrm{H}_{2} \mathrm{O}_{2}$. The resulting lignin functionality and structure was evaluated by pyrolysis-gas chromatography/mass spectrometry, solid-state ${ }^{13} \mathrm{C}$ nuclear magnetic resonance, Fourier transform infrared, and chemical analysis. The condensation degree of $\mathrm{BL}$ and its $\mathrm{COOH}$ and aliphatic $\mathrm{OH}$ group contents increased significantly, whereas the polymer structure was maintained. Under optimal conditions with $\mathrm{POM} / \mathrm{H}_{2} \mathrm{O}_{2}$, the sorption capacity of lignins toward $\mathrm{Cd}(\mathrm{II})$ and $\mathrm{Pb}$ (II) was increased threefold and twofold, respectively.
\end{abstract}

Keywords: adsorption of metals, environmental remediation, heavy metals, lignins, oxidative modification, polyoxometalates (POM), pyrolysis-GC/MS

*Corresponding author: Tatiana Dizhbite, Latvian State Institute of Wood Chemistry, Riga, Latvia, e-mail: Icl@edi.lv Lilija Jashina, Galina Dobele, Anna Andersone, Oskar Bikovens and Galina Telysheva: Latvian State Institute of Wood Chemistry, Riga, Latvia

Dmitry Evtuguin: CICECO and Chemistry Department, Aveiro University, Campus Universitario de Santiago, Aveiro, Portugal

\section{Introduction}

The biorefinery concept is adopted from petroleum refinery, where an array of products is produced from crude oil without wastes. A branch of the biorefinery efforts is dealing with the modification of established biomass conversion processes, for example, by the introduction of a prehydrolysis step before pulping, and the conversion of dissolved carbohydrates to value-added products (Gütsch and Sixta 2011; Hörhammer et al. 2011; Schütt et al. 2011; Testova et al. 2011). The development of new processes based on organic solvents and acids (organosolv process) has also a long tradition (Jiménez et al. 1998, 2004; Saake et al. 1998; Abad et al. 2002; Lehnen et al. 2002; Claus et al. 2004; Yawalata and Paszner 2006; Iakovlev et al. 2009). The ideal behind this research is a mild separation of cellulose, hemicelluloses, and lignin and the production of value-added products of them as polymers, food, and chemicals. Power and heat should be produced only from the unavoidable wastes. Biorefinery also concerns with the utilization of lignin as a by-product of pulping.

In the present article, an organosolv process of wheat straw based on acetic and formic acid digestion, which is realized in association with two industrial partners (CIMV S.A., Levallois Perret, France and DSM Bio-based Products \& Services B.V., Delft, The Netherlands), is in focus. The scientific developments are accompanied within an EU project called Biocommodity Refinery (BIOCORE) under the participation of 25 institutions. CIMV products are cellulose, sugar syrup, and Biolignin (BL). The details are described by Lam et al. (2001), Delmas (2008), and Delmas et al. (2011). The utilization of BL as an adsorbent material will be addressed in the present article.

Lignins in situ (native lignins) are multifunctional phenolic polymers containing hydroxyl, carboxyl, and carbonyl groups (Sarkanen and Ludwig 1971; Fengel and Wegener 1989; Lin and Dence 1992). The native lignins obtained after pulping are called technical lignins, because their structure is modified during digestion, also in the case of acid hydrolysis of an organosolv process. The porous structure of technical lignins is not highly developed. Nevertheless, they are utile as adsorbents/ sequestrants of heavy metals, oil products, phenols and chlorophenols, detergents, etc. (Dizhbite et al. 1999; Basso et al. 2002; Babel and Kurniawan 2003; Boving and Zhang 2004; Demirbas 2004; Crist et al. 2005; Mohan et al. 2006; Rachkova et al. 2006; Guo et al. 2008; Harmita et al. 2009). The mechanism of the sorption includes physical adsorption, hydrogen bonding, coordination and covalent linking, and acid-base interaction. The various methods 
of functionalization of lignins were proposed to expand their potential for bioremediation, that is, adsorption of not desired compounds from the environment (Dizhbite et al. 1999; Suhas et al. 2007).

The oxidative conversion of kraft lignins by means of polyoxometalates (POMs) is one of the promising approaches in this context (Dos Santos et al. 2012). The oxidation of eucalypt kraft lignin by the POM Na $\left.5 \mathrm{PMo}_{10} \mathrm{~V}_{2} \mathrm{O}_{40}\right]$, alone or in combination with laccase, resulted in enrichment with carboxylic and carbonyl groups. The oxidized lignin had an improved sorption capacity toward Cd and $\mathrm{Hg}$; more precisely, up to $15 \%$ of these transition metals were adsorbed.

POMs are effective for the removal of residual lignin from pulp (Kubelka et al. 1992; Rabelo et al. 2008). Weinstock et al. (1998) are the pioneers in this field, because they investigated in several studies how the POMs act in $\mathrm{O}_{2}$ - or $\mathrm{O}_{2} / \mathrm{H}_{2} \mathrm{O}_{2}$-containing media for the delignification and bleaching of technical cellulose. They clarified that POMs are capable either to partially oxidize lignin with moderate decomposition of the side chains, demethylation, oxidation to quinones, cross-polymerization, and cleavage of the aromatic ring or, alternatively, to deeply oxidize lignin to products with low molecular weight. A problem is that POMs need to be applied in stoichiometric amounts. Evtuguin et al. (2000) confirmed with model compounds that $\left[\mathrm{PMo}_{7} \mathrm{~V}_{5} \mathrm{O}_{40}\right]^{8-}$ leads below $60^{\circ} \mathrm{C}$ to partially oxidized lignin without depolymerization. POMs do not promote radical-chain oxidizing reactions; thus, the polysaccharides are not degraded. Gaspar et al. (2004) demonstrated in pilot-scale trials that they are suitable for the oxygen delignification of kraft pulp. Guo et al. (2011) confirmed that Mo-containing POMs are efficient for the activation of $\mathrm{H}_{2} \mathrm{O}_{2}$ bleaching and delignification of pulp.

The aim of the present work was the oxidative modification of BL to make it more suitable for bioremediation applications (heavy metal adsorption). The oxidative systems $\mathrm{POM} / \mathrm{O}_{2}$ and $\mathrm{POM} / \mathrm{H}_{2} \mathrm{O}_{2}$ will be addressed. Based on literature data (Guo et al. 2011) and our preliminary study with $\left[\mathrm{PMo}_{12} \mathrm{O}_{40}\right]^{3-}$ and $\left[\mathrm{PMo}_{7} \mathrm{~V}_{5} \mathrm{O}_{40}\right]^{8-}$ (Dizhbite et al. 2011), phosphomolybdic acid $\mathrm{H}_{3}\left[\mathrm{PMo}_{12} \mathrm{O}_{40}\right]$ was selected as a good candidate for oxidative lignin modification. $\mathrm{H}_{2} \mathrm{O}_{2}$ as co-oxidant permits the performance under mild reaction conditions $\left(1 \mathrm{bar}, 20^{\circ} \mathrm{C}\right)$. The resulting lignins were evaluated by pyrolysis-gas chromatography/mass spectrometry (Py-GC/MS), solid-state ${ }^{13} \mathrm{C}$ nuclear magnetic resonance (NMR) and Fourier transform infrared (FTIR) spectroscopy, and chemical analysis. The sorption properties of the lignins will be evaluated toward cadmium and lead. These elements are ubiquitous in the environment because they are applied in metallurgy, chemical industries, electrogalvanization, textile production, fuels, just to mention a few.

\section{Materials and methods}

\section{Materials}

BL was extracted from wheat straw at atmospheric pressure with a mixture of acetic acid/formic acid/water 30:55:15 (v/v/v) at the CIMV pilot plant (Pomacle, France) (Delmas et al. 2011). Klason lignin $(89 \pm 1 \%)$ was determined according to Tappi T222. The parent BL was dried under vacuum at $40^{\circ} \mathrm{C}$ (oven VACIOTEM-T, Selecta, Barcelona, Spain) to $<1 \%$ moisture content and the fraction with particle sizes of $d<0.25 \mathrm{~mm}$ was submitted to modification.

Phosphomolybdic acid $\mathrm{H}_{3}\left[\mathrm{PMo}_{12} \mathrm{O}_{40}\right]$ of A.C.S. grade was purchased from Acros Organics (Geel, Belgium). $\mathrm{Cd}\left(\mathrm{NO}_{3}\right)_{2} \cdot 4 \mathrm{H}_{2} \mathrm{O}$ and $\mathrm{Pb}\left(\mathrm{NO}_{3}\right)_{2}$, both of analytical grade, were from Lach-ner (Neratovice, Czech Republic). The $35 \% \mathrm{H}_{2} \mathrm{O}_{2}$ solution from Reachem (Bratislava, Slovakia) and the other chemicals from Sigma-Aldrich (Munich, Germany) were also of analytical grade. All test solutions were freshly prepared with deionized water.

\section{Oxidative modification of lignin}

The parameters were preselected according to Evtuguin et al. (2000) and Dizhbite et al. (2011). The details are listed in Table 1. In the 11 stainless still reactor (PARR model 4848, Parr Instrument, Moline, IL, USA) $5 \mathrm{~g}$ of lignin were suspended with $250 \mathrm{ml}$ of 0.002 or $0.05 \mathrm{~mol} \mathrm{l}^{1}$ phosphomolybdic acid. For experiments with $\mathrm{POM} / \mathrm{H}_{2} \mathrm{O}_{2}$ system, $\mathrm{H}_{2} \mathrm{O}_{2}$ aqueous solution $\left(4 \mathrm{~mol} \mathrm{l}^{1}\right)$ was added to the reaction mixture. The oxygen pressure was 1 bar. The solid reaction product was washed with deionized water until $\mathrm{pH} 4$ ( $\mathrm{pH}$ of the parent BL suspension) and dried under vacuum at $40^{\circ} \mathrm{C}$ for $24 \mathrm{~h}$. The dried samples were ground in a Retch Ball Mill MM200 (Retch, Haan, Germany) at the frequency of $30 \mathrm{~s}^{1}$ for $30 \mathrm{~min}$ and then analyzed.

\section{Chemical analysis}

Elemental analysis: CHNSO analyzer ELEMENTAR (Vario MACRO, Hanau, Germany). Analysis of functional groups: according to Zakis (1994). OMe determination: according to Vieböck and Schwappach

Table 1 Experimental conditions used for the oxidative modification of $B L$ and yields of modified lignins.

\begin{tabular}{|c|c|c|c|c|c|c|}
\hline Sample & $\begin{array}{r}\text { [POM] } \\
\left(\mathrm{mol} \mathrm{l}^{-1}\right)\end{array}$ & $\begin{array}{r}{\left[\mathrm{H}_{2} \mathrm{O}_{2}\right]} \\
\left(\mathrm{mol} \mathrm{l}^{-1}\right)\end{array}$ & $\mathrm{pH}$ & $\begin{array}{r}\text { Temp. } \\
\left({ }^{\circ} \mathrm{C}\right)\end{array}$ & $\begin{array}{r}\text { Time } \\
\text { (h) }\end{array}$ & $\begin{array}{r}\text { Yield } \\
(\%)\end{array}$ \\
\hline BL-POM-1 & 0.002 & 0 & 2.3 & 60 & 2 & $91 \pm 2$ \\
\hline BL-POM-2 & 0.05 & 0 & 1.1 & 40 & 2 & $88 \pm 2$ \\
\hline BL-POM-3 & 0.05 & 0 & 1.1 & 60 & 2 & $89 \pm 2$ \\
\hline BL-POM $/ \mathrm{H}_{2} \mathrm{O}_{2}-4$ & 0.002 & 4.0 & 2.3 & 20 & 2 & $86 \pm 3$ \\
\hline BL-POM $/ \mathrm{H}_{2} \mathrm{O}_{2}-5$ & 0.002 & 4.0 & 2.3 & 20 & 8 & $86 \pm 1$ \\
\hline
\end{tabular}


in a Zeisel apparatus (domestic glassware). The contents of phenolic hydroxyl $\left(\mathrm{OH}_{\mathrm{phen}}\right)$ and carboxylic $(\mathrm{COOH})$ groups were determined by acid-base conductometric titration under $\mathrm{N}_{2}$ (automatic titration device ABU901, Radiometer Analytical, Villeurbanne, France) coupled with Conductometer CDM 210 (Radiometer Analytical, Villeurbanne, France) and Titration manager TIM900 (Radiometer Analytical, Villeurbanne, France). Aliphatic $\mathrm{OH}$ groups: via determination of the total $\mathrm{OH}$ group content by acetylation with acetic anhydride and potentiometric titration of free acetic acid with $0.1 \mathrm{~N} \mathrm{NaOH}$ solution in water, taking into account the percentage of $\mathrm{COOH}$ groups in the sample (Zakis 1994). $\mathrm{OH}_{\text {aliph }}=\mathrm{OH}_{\text {total }}-\mathrm{OH}_{\text {phen }}$. The content of carbonyl groups was measured by oximation by conductometric titration (Zakis 1994). All analyses were done in triplicate at least. All results are expressed on a dry weight (oven drying at $105^{\circ} \mathrm{C}$ for $18 \mathrm{~h}$ ) and ash (ash: $700^{\circ} \mathrm{C}$ for $3 \mathrm{~h}$ in a Carbolite furnace ELF 11/6B, Hope Valley, UK) free basis.

\section{Analytical pyrolysis (Py-GC/MS)}

Instrument: Frontier Lab (Koriyama, Japan) Micro Double-shot Pyrolyzer Py-2020iD (pyrolysis temperature $500^{\circ} \mathrm{C}$, heating rate $600^{\circ} \mathrm{C} \mathrm{s}^{1}$ ) directly coupled with the Shimadzu GC/MS-QP 2010 apparatus, Kyoto, Japan, (EI 70 eV). Capillary column: RTX-1701 (Restec, San Diego, CA, USA), $60 \mathrm{~m} \times 0.25 \mathrm{~mm} \times 0.25 \mu \mathrm{m}$ film. Temperatures: injector $250^{\circ} \mathrm{C}$, ion source $250^{\circ} \mathrm{C}$. MS scan range $m / z 15-350$, He as carrier gas (1 $\mathrm{ml} \mathrm{min}^{1}$ ), split ratio 1:30. Inserted mass: 1-2 mg (residual MC of sample $<1 \%$ ). Oven program: $1 \mathrm{~min}$ isothermal at $60^{\circ} \mathrm{C}$ and then $6^{\circ} \mathrm{C} \min ^{1}$ to $270^{\circ} \mathrm{C}$ (held for $10 \mathrm{~min}$ ). The apparatus was modified by the installation of the splitter of gas-carrier flow Vitreous Silica Outlet Splitter VSOS (SGE, Ringwood, Victoria, Australia) to operate FID and MS detectors simultaneously. Internal standard for quantification: fluoranthene. Identification: Library MS NIST 147.LI13. The summed peak areas of the relevant peaks were normalized to $100 \%$ and the data for five repetitive experiments were averaged for presentation.

\section{NMR spectroscopy}

${ }^{13} \mathrm{C}$ CP-MAS NMR instrument: Bruker Avance 400 spectrometer (Bruker BioSpin, Billerica, MA, USA). Samples were packed into a zirconia rotor sealed with Kel-FTM caps and spun at $7 \mathrm{kHz}$. Acquisition parameters: 5000 scans with a $90^{\circ}$ proton pulse, a cross-polarization contact time of $1 \mathrm{~ms}$, and a recovery delay of $2.5 \mathrm{~s}$. Spectra were processed with Bruker software XWIN-NMR-3.1 (Bruker BioSpin, Billerica, MA, USA).

\section{FTIR spectroscopy}

Instrument: Spectrum One (Perkin-Elmer, Beaconsfield, UK) FTIR spectrometer (KBr pellet technique); resolution: $4 \mathrm{~cm}^{1}$; number of scans: 64 . Before analyses, the lignin samples were mixed with potassium ferricyanide $\mathrm{K}_{3} \mathrm{Fe}\left[(\mathrm{CN})_{6}\right]$ as an internal standard at a proportion 1:5. Baseline correction was carried out by the Spectrum version 5.0 software (Perkin-Elmer, Beaconsfield, UK) and the resulting spectra were normalized to the intensity of $\mathrm{CN}$ stretching band at $2140 \mathrm{~cm}^{1}$.

\section{Characterization of the porous structure}

Method applied: $\mathrm{N}_{2}$ adsorption-desorption isotherms method. Temperature: $-196^{\circ} \mathrm{C}$ according to the recommendations of the International Union of Pure and Applied Chemistry (Sing et al. 1985). Instrument: KELVIN 1042 sorptometer (Costech International, Cernusco $\mathrm{S} / \mathrm{Nav}$, Milan, Italy). Specific surface area $\left(S_{\mathrm{BET}}\right)$ was calculated by applying the Brunauer-Emmett-Teller (BET) equation. The pore size distribution was calculated by the Barrett-Joyner-Halenda (BJH) method (Gregg and Sing 1982).

\section{Heavy metals adsorption}

The sorption of cadmium and lead was observed by the batch method. All experiments were carried out in acetate buffer ( $\mathrm{pH}$ 5.0) at $20^{\circ} \mathrm{C}$ varying metal initial concentration in the solution in the range from $1 \times 10^{5}$ up to $1 \times 10^{3} \mathrm{~mol} 1^{1}$. A $200 \mathrm{mg}$ sample was placed into $50 \mathrm{ml}$ Pyrex flasks. The solution of the metal salt $(20 \mathrm{ml})$ was added to the flask with lignin, and the flask was shaken for $24 \mathrm{~h}$. The preexperiments showed that this time is sufficient to achieve adsorption equilibrium. At least four replicated experiments were carried out. At the end of each batch experiment run, an aliquot of solution was centrifuged at 20,000 rpm for $5 \mathrm{~min}$ and the $\mathrm{Cd}$ or $\mathrm{Pb}$ concentration in supernatant was determined by atomic absorption spectroscopy (AA-6300, Shimadzu apparatus, Kyoto, Japan). The blank solutions of the metal salts were treated similarly and the concentration at the end of each experiment was taken as the initial one. The adsorption at equilibrium, $q_{\mathrm{e}}\left(\mathrm{mol} \mathrm{g} \mathrm{g}^{1}\right.$ lignin), was calculated as $Q_{\mathrm{e}}=V \times\left(C_{0}-C_{\mathrm{e}}\right) /$ $\left(1000 \times m_{\mathrm{s}}\right)$, where $C_{0}$ and $C_{\mathrm{e}}$ are the initial and equilibrium concentrations of metal solutions ( $\left.\mathrm{mol} \mathrm{l}^{1}\right), V$ is the solution volume (ml), and $m_{s}$ is the mass of lignin $(\mathrm{g})$.

\section{Results and discussion}

\section{Influence of modification conditions}

The oxidative modification of BL was carried out aiming at higher amounts of oxygen-containing functional groups, namely, carboxyl, carbonyl, and aliphatic hydroxyl groups in lignin without depolymerization. An elemental analysis (Table 2) shows a significant increase of oxygen contents. The analysis of functional groups (Table 3 ) indicated that

Table 2 Elemental composition of parent and modified BL.

\begin{tabular}{lrrrr}
\hline Sample & N (\%) & C (\%) & H (\%) & O (\%) \\
\hline BL & $1.6 \pm 0.1$ & $62.1 \pm 0.3$ & $5.5 \pm 0.1$ & $30.8 \pm 0.7$ \\
BL-POM-1 & $1.6 \pm 0.1$ & $60.1 \pm 0.2$ & $5.8 \pm 0.1$ & $32.4 \pm 0.2$ \\
BL-POM-2 & $1.6 \pm 0.1$ & $54.3 \pm 0.2$ & $5.8 \pm 0.1$ & $38.3 \pm 0.2$ \\
BL-POM-3 & $1.4 \pm 0.1$ & $50.6 \pm 0.1$ & $5.8 \pm 0.1$ & $42.1 \pm 0.1$ \\
BL-POM $/ \mathrm{H}_{2} \mathrm{O}_{2}-4$ & $1.5 \pm 0.1$ & $58.7 \pm 0.2$ & $5.4 \pm 0.1$ & $34.4 \pm 0.4$ \\
BL-POM $/ \mathrm{H}_{2} \mathrm{O}_{2}-5$ & $1.5 \pm 0.1$ & $57.6 \pm 0.2$ & $5.4 \pm 0.1$ & $35.5 \pm 0.4$ \\
\hline
\end{tabular}


Table 3 Functional composition of parent and modified BL.

\begin{tabular}{lrrrrr}
\hline \multirow{2}{*}{ Sample } & \multicolumn{5}{c}{ Analytical data (mmol g-1) } \\
\cline { 2 - 6 } & $\mathbf{O C H}_{3}$ & $\mathbf{C}=\mathbf{0}$ & $\mathbf{O H}_{\text {cooH }}$ & $\mathbf{O H}_{\text {aliph }}$ & $\mathbf{O H}_{\text {phen }}$ \\
\hline $\mathrm{BL}$ & $3.1 \pm 0.1$ & $1.4 \pm 0.1$ & $1.2 \pm 0.5$ & $4.9 \pm 0.1$ & $1.2 \pm 0.2$ \\
$\mathrm{BL}-\mathrm{POM}-1$ & $2.9 \pm 0.2$ & $1.4 \pm 0.2$ & $1.6 \pm 0.1$ & $5.9 \pm 0.1$ & $0.9 \pm 0.1$ \\
$\mathrm{BL}-\mathrm{POM}-2$ & $2.7 \pm 0.3$ & $1.4 \pm 0.1$ & $2.7 \pm 0.1$ & $5.0 \pm 0.2$ & $0.9 \pm 0.1$ \\
$\mathrm{BL}-\mathrm{POM}-3$ & $2.5 \pm 0.1$ & $1.4 \pm 0.1$ & $3.0 \pm 0.2$ & $6.4 \pm 0.2$ & $0.7 \pm 0.1$ \\
$\mathrm{BL}-\mathrm{POM} / \mathrm{H}_{2} \mathrm{O}_{2}-4$ & $2.4 \pm 0.1$ & $1.7 \pm 0.1$ & $2.7 \pm 0.1$ & $5.1 \pm 0.2$ & $1.5 \pm 0.1$ \\
$\mathrm{BL}-\mathrm{POM} / \mathrm{H}_{2} \mathrm{O}_{2}-5$ & $2.3 \pm 0.1$ & $1.8 \pm 0.1$ & $2.9 \pm 0.1$ & $7.1 \pm 0.3$ & $1.3 \pm 0.1$ \\
\hline
\end{tabular}

the increase in oxygen content was related mostly to the formation of carboxyl groups. An increased content of $\mathrm{OH}_{\text {aliph }}$ groups was detected only in the samples BL-POM-3 and BL-POM/ $\mathrm{H}_{2} \mathrm{O}_{2}-5$. This can be partly the results of a partial deacetylation of wheat straw lignin, which is acetylated at C-g atoms (Del Rio et al. 2012).

The largest increment of carboxyl, carbonyl, and aliphatic hydroxyl groups was observed, when BL was oxidized in the system POM $/ \mathrm{H}_{2} \mathrm{O}_{2}$ (sample BL-POM/ $/ \mathrm{H}_{2} \mathrm{O}_{2}-5$ ) at $20^{\circ} \mathrm{C}$ with the $0.002 \mathrm{~mol} \mathrm{l}^{-1}$ concentration of the catalyst. In experiments with the system $\mathrm{POM} / \mathrm{O}_{2}$, similar results could be achieved only at 20 times elevated concentration of phosphomolybdic acid and at a higher temperature of $60^{\circ} \mathrm{C}$ (BL-POM-3). The content of carbonyl groups increased significantly only after the treatment in the presence of $\mathrm{H}_{2} \mathrm{O}_{2}$ (samples BL-POM/ $\mathrm{H}_{2} \mathrm{O}_{2}-4$ and -5). These features may be tentatively explained by a much easier formation of peroxomolybdate in the presence of hydrogen peroxide, which readily reacts with lignin. It is believed that peroxocomplexes of molybdate are responsible for the lignin oxidation in presence of $\mathrm{H}_{2} \mathrm{O}_{2}$ (Taube et al. 2008).

The demethoxylation reactions occur upon BL catalytic oxidation as indicated by decreasing OMe groups (Table 3 ). This is especially pronounced in the reaction system POM/ $\mathrm{H}_{2} \mathrm{O}_{2}$. Hence, the increased amounts of carbonyl and phenolic hydroxyl groups in corresponding oxidized lignins may be assigned, at least partially, to the formation of quinone and hydroquinone moieties. The small decrease of $\mathrm{OH}_{\text {phen }}$ in lignins oxidized in the reaction system $\mathrm{POM} / \mathrm{O}_{2}$ could be explained by condensation reactions (including oxidative coupling), which led to molecular weight increment as shown previously in the aerobic lignin with phosphomolybdovanadates (Dos Santos et al. 2012).

Based on the results of chemical analyses, the lignins oxidized in the reaction system $\mathrm{POM} / \mathrm{O}_{2}$ at $60^{\circ} \mathrm{C}$ $\left(C_{\mathrm{POM}}=0.05 \mathrm{~mol} \mathrm{l}^{-1}\right)$ for $2 \mathrm{~h}$ and in the system POM $/ \mathrm{H}_{2} \mathrm{O}_{2}$ at $20^{\circ} \mathrm{C}\left(C_{\mathrm{POM}}=0.002 \mathrm{moll}^{-1}\right)$ for $8 \mathrm{~h}$, provided modified lignins in yields of approximately $85 \%$ and with the highest increment of the targeted functional groups. These lignins were selected for sorption experiments and detailed characterization by FTIR and ${ }^{13} \mathrm{C}$ NMR spectroscopy and analytical pyrolysis (Py-GC/MS).

The fingerprint region of FTIR spectra of BL (Figure 1) before and after oxidation exhibits typical guaiacyl-syringyl lignin patterns (Faix 1991a). A decrease of absorption intensity at $1510 \mathrm{~cm}^{-1}$ (BL oxidized in $\mathrm{POM} / \mathrm{H}_{2} \mathrm{O}_{2}$ ) reveals some degradation of aromatic structures. Moreover, an increased carbonyl group intensity $\left(1600-1720 \mathrm{~cm}^{-1}\right)$ is perceptible. The band at $1720 \mathrm{~cm}^{-1}$ corresponds to unconjugated carboxylic groups and that at $1650 \mathrm{~cm}^{-1}$ to various carbonyl groups, including quinones and conjugated ones. Probably, the aromatic rings opening led to the formation of muconic acid-type carboxyl group formation. The spectral condensation index calculated according to Faix (1991b) (see also Xiao et al. 2012) of the BL-POM-3 sample (0.60) was higher than that for the untreated $\mathrm{BL}$ (0.51). Accordingly, the condensation reactions occur leading to the consumption of some $\mathrm{OH}_{\text {phen }}$ groups in the system $\mathrm{POM} / \mathrm{O}_{2}$.

In the solid-state ${ }^{13} \mathrm{C}$ NMR spectra, a significant signal increment was observed at 123-127 ppm (quaternary aromatic carbon atoms; see Chen and Robert 1988; Hawkes et al. 1993) with respect to resonances at $100-160 \mathrm{ppm}$ (carbons in aromatic structures) in the system POM/ $\mathrm{O}_{2} / \mathrm{BL}$ (Figure 2; Table 4). This is in agreement with the interpretation of the FTIR spectra in terms of an elevated degree of condensation, which leads to the formation of new quaternary $\mathrm{C}-\mathrm{C}$ bonds. The condensation reactions were more pronounced for BL oxidized by $\mathrm{POM} / \mathrm{O}_{2}$ than by $\mathrm{POM} / \mathrm{H}_{2} \mathrm{O}_{2}$ (Figure 2, BL-POM-3 and BL-POM $/ \mathrm{H}_{2} \mathrm{O}_{2}$ samples, respectively).

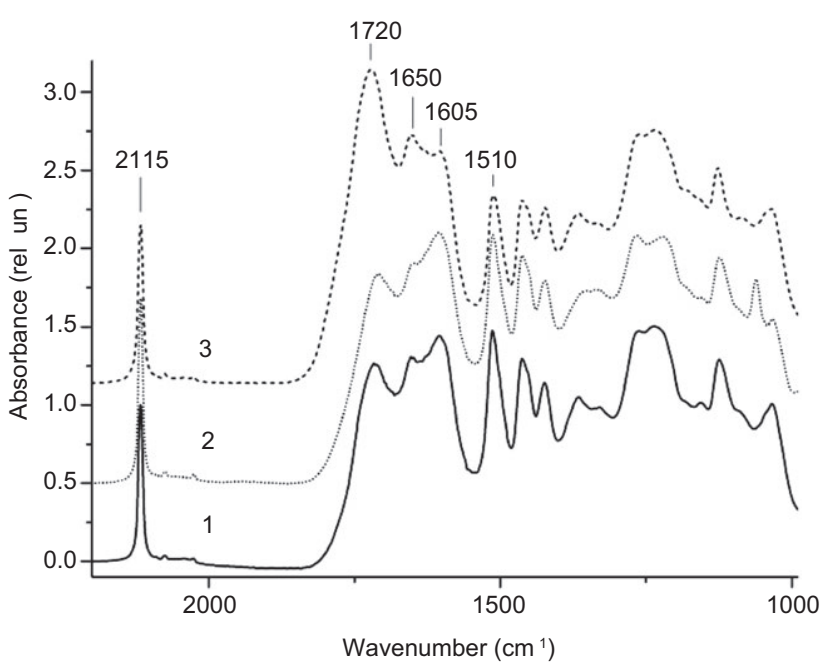

Figure 1 FTIR spectra of lignin samples: (1) BL, (2) BL-POM-3, and (3) BL-POM- $\mathrm{H}_{2} \mathrm{O}_{2}-5$. 


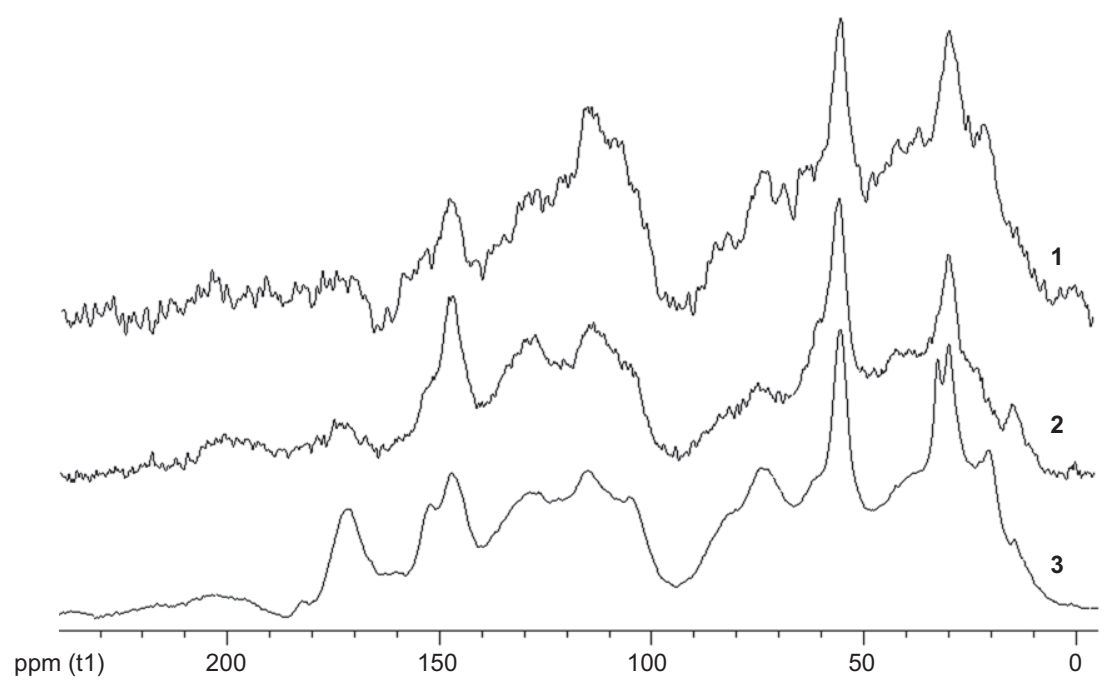

Figure $2{ }^{13} \mathrm{C}$ CP-MAS NMR spectra of lignin samples: (1) BL, (2) BL-POM-3, and (3) BL-POM- $\mathrm{H}_{2} \mathrm{O}_{2}-5$.

Table 4 Results of semiquantitative analysis of BL and its oxidized analogues by solid-state ${ }^{13} \mathrm{C}$ NMR.

\begin{tabular}{|c|c|c|c|c|c|}
\hline \multirow[t]{2}{*}{ Sample } & \multicolumn{4}{|c|}{ Integral intensity of NMR signal (\%) } & \multirow[t]{2}{*}{ Degree of aromatization $^{b}$} \\
\hline & 0-50 ppm & 50-100 ppm & $100-160 \mathrm{ppm}$ & $165-210 \mathrm{ppm}$ & \\
\hline $\mathrm{BL}$ & 43 & 33 & 22 & 2 & 18 \\
\hline BL-POM-3 & 23 & 29 & 42 & 6 & 29 \\
\hline BL-POM $/ \mathrm{H}_{2} \mathrm{O}_{2}-5$ & 29 & 29 & 34 & 8 & 22 \\
\hline
\end{tabular}

${ }^{a}$ Normalized intensity of the signal in the ppm ranges indicated. ${ }^{b}$ Degree of aromatization: (Integral intensity in the range 110-140 ppm)/ (Integral intensity in the range 0-140 ppm) (McBeath et al. 2011).

The spectra of oxidized lignins showed noticeable higher signals at 165-210 ppm assigned to the carbons of carboxyl and carbonyl groups. Thus, these results can be interpreted as carbons in $\mathrm{COOH}$ groups of benzoic acid and/or muconic acid type formed as a result of benzene ring opening (Hawkes et al. 1993; Evtuguin et al. 2009). The set of signals at 192-194 and 196-205 ppm was assigned to carbonyls in benzaldehyde or cinnamaldehyde and ketone carbonyl groups, respectively (Chen and Robert 1988). The increasing aromaticity of lignin oxidized in the system $\mathrm{POM} / \mathrm{O}_{2}$ (BL-POM-3 sample) together with decreasing intensities at 0-100 ppm (Table 4) may be indicative for the demethoxylation and degradation of aliphatic side chains.

Lignin condensation was confirmed by the results of Py-GC/MS analysis (Table 5). Areas of pyrograms peaks, typical for lignin degradation products, were summed up and normalized to $100 \%$ to facilitate the overview of changes caused by oxydation. The partial degradation of side chains upon oxidation is evidenced by the increase in relative amounts of guaiacyl and syringyl derivatives without and with shortened side chains $[\mathrm{Ph}+\mathrm{Ph}(\mathrm{C} 1)+\mathrm{Ph}(\mathrm{C} 2)]$ (Tamminen et al. 2004). The ratio between $[\mathrm{Ph}+\mathrm{Ph}(\mathrm{C} 1)+\mathrm{Ph}(\mathrm{C} 2)] / \mathrm{Ph}(\mathrm{C} 3)$ increased from 6.5 (BL) to 13.9 (BL-POM-3) and 8.2 (BL-POM/ $\left.\mathrm{H}_{2} \mathrm{O}_{2}-5\right)$. Clearly, the degradation of lignin side chains is more pronounced in the system POM $/ \mathrm{O}_{2}$ (Ohra-aho et al. 2005).

The oxidative modification in the samples BL-POM-3 and BL-POM $/ \mathrm{H}_{2} \mathrm{O}_{2}$ led to 4- and 1.5-fold elevated amount of the fraction of phenyl and benzene derivatives (Table 6). This is also a sign of condensation reactions. The less intensive development of condensation reactions upon BL modification in the system $\mathrm{POM} / \mathrm{H}_{2} \mathrm{O}_{2}$ could be connected with the formation of reactive peroxomolybdates in the presence of $\mathrm{H}_{2} \mathrm{O}_{2}$. This provides an efficient oxidation as evidenced by the formation of carboxyl and carbonyl groups. In the system $\mathrm{POM} / \mathrm{O}_{2}$, carboxyl group formation is accompanied by lignin condensation.

For applications in environmental remediation, for example, for the adsorption of heavy metals, the condensation of lignins is mainly advantageous because it diminishes lignin leachability in aqueous solutions. In fact, the solubility of oxidized BL in DMSO and aqueous dioxane solutions decreased by $30-100 \%$ depending on the severity of the oxidation conditions. 
Table 5 Distribution of lignin-derived volatile products in pyrolysates of BL samples normalized to $100 \%$.

\begin{tabular}{|c|c|c|c|}
\hline \multirow[t]{2}{*}{ Compound } & \multicolumn{3}{|c|}{ Normalized peak areas (\%) } \\
\hline & BL & BL-POM-3 & $\mathrm{BL}-\mathrm{POM} / \mathrm{H}_{2} \mathrm{O}_{2}-5$ \\
\hline Methylbenzene & 0.9 & 4.5 & 0.4 \\
\hline 1,4-Dimethylbenzene & 0.1 & 0.9 & 2.2 \\
\hline Phenylethene & 0.1 & 0.8 & 0.3 \\
\hline Methoxybenzene & Trace & 1.2 & 0.7 \\
\hline 1-Methoxy-4-methylbenzene & Trace & 0.6 & 0.5 \\
\hline Phenol & 4 & 26.7 & 0.8 \\
\hline 1-Ethenyl-4-methoxybenzene & Trace & Trace & Trace \\
\hline 2-Methylphenol & 0.8 & 4.5 & 0.4 \\
\hline 4-Methylphenol & 2.9 & 3.7 & 0.2 \\
\hline 3-Methylphenol & 0.7 & 7.1 & 0.6 \\
\hline 2-Methoxy-3-methylphenol & 0.1 & 0.3 & Trace \\
\hline 3,4-Dimethylphenol & 0.7 & 1.7 & 5.3 \\
\hline 1,2-Dimethoxy-4-methylbenzene & 0.1 & Trace & 6.1 \\
\hline 4-Ethylphenol & 1.3 & 3.5 & Trace \\
\hline $3^{\prime}, 5^{\prime}$-Dihydroxyacetophenone & 0.2 & Trace & 1.1 \\
\hline 3-Methoxy-5-methyphenol & 0.4 & Trace & 2.0 \\
\hline 2-Allylphenol & 0.2 & Trace & 0.5 \\
\hline$\Sigma$ of benzene and phenol derivatives & 12.6 & 54.6 & 22.2 \\
\hline 2-Methoxyphenol & 10.3 & 9.1 & 11.1 \\
\hline 2-methoxy-4-methylphenol & 10.9 & 9.3 & 9.9 \\
\hline 4-Ethyl-2-methoxyphenol & 3.8 & 3.3 & 4.6 \\
\hline 4-Vinyl-2-metoxyphenol & 27.8 & 23.8 & 29.4 \\
\hline 4-Allyl-2-methoxyphenol & 0.8 & 0.8 & 0.4 \\
\hline 2-Methoxy-4-propylphenol & 0.5 & 0.2 & 0.4 \\
\hline 2-Methoxy-4-[(Z)-prop-1-enyl]phenol & 0.7 & 0.6 & 0.7 \\
\hline 2-Methoxy-4-[(E)-prop-1-enyl]phenol & 4.1 & 2.4 & 3.3 \\
\hline 4-Hydroxy-3-methoxybenzaldehyde & 0.9 & 4.9 & 0.9 \\
\hline 1-(G)ethanone & 0.6 & 1.6 & 0.6 \\
\hline 1-(G)propan-2-one & 0.6 & 0.3 & 0.5 \\
\hline 1-(G)propan-1-one & 0.3 & 0.2 & 0.2 \\
\hline 1-(G)propan-1-one-1-oxy & 1.2 & 4.4 & 1.0 \\
\hline 2,6-Dimethoxyphenol & 6.4 & 7.6 & 7.5 \\
\hline 2,6-Dimethoxy-4-methylphenol & 5.5 & 6.3 & 6.1 \\
\hline 4-Ethyl-2,6-dimethoxyphenol & 0.9 & 1.0 & 0.9 \\
\hline 4-Vinyl-2,6-dimethoxyphenol & 3.1 & 2.9 & 2.5 \\
\hline 4-Allyl-2,6-dimethoxyphenol and 2,6-dimethoxy-4-propylphenol & 1.2 & 0.8 & 0.9 \\
\hline 2,6-Dimethoxyphenol derivative & 0.2 & 0.4 & 0.2 \\
\hline 2,6-Dimethoxy-4-[(E)-prop-1-enyl]phenol & 3.2 & 2.1 & 2.4 \\
\hline 4-Hydroxy-3,5-dimethoxybenzaldehyde & 0.3 & 4.7 & 0.3 \\
\hline 1-(S)ethanone & 1.7 & 1.5 & 0.9 \\
\hline 1-(S)propan-2-one & 0.3 & 0.1 & 0.3 \\
\hline 1-(S)propan-1-one & 0.1 & 0.2 & 0.2 \\
\hline 1-(S)propan-1-one-1-oxy & 0.6 & 2.7 & 0.7 \\
\hline
\end{tabular}

G, guaiacyl=4-hydroxy-3-methoxyphenyl; S, syringyl=4-hydroxy-3,5-dimethoxypheny.

Table 6 Summarized results of Py-GC/MS analysis of lignin samples.

\begin{tabular}{lcccr}
\hline Sample & & \multicolumn{3}{c}{$\boldsymbol{\Sigma}$ of peak areas (\%) } \\
\cline { 2 - 5 } & Bz & Ph & G & S \\
\hline BL & 1.4 & 11.1 & 63.6 & 25.1 \\
BL-POM-3 & 8.0 & 46.6 & 40.9 & 4.5 \\
BL-POM $/ \mathrm{H}_{2} \mathrm{O}_{2}-5$ & 5.7 & 16.5 & 58.0 & 18.8 \\
\hline
\end{tabular}

$\mathrm{Bz}$, benzene; G, guaiacol; Ph, phenol; S, syringol.

\section{Adsorption properties of modified BL}

The effect of oxidative treatment on the porosity of BL was studied - to our knowledge, for the first time - by the $\mathrm{N}_{2}$ sorption-desorption method. The values concerning the $S_{\mathrm{BET}}$ (average, $24 \mathrm{~m}^{2} \mathrm{~g}^{-1}$ ) and pore volumes (average, $153 \mathrm{~mm}^{3} \mathrm{~g}^{-1}$ ) (Table 7) arealtogether significantly higher than those reported in the literature for other organosolv and kraft lignins (Telysheva et al. 2006; Harmita et al. 2009). 
Table 7 Characterization of porous structure of BL samples.

\begin{tabular}{lrr}
\hline Sample & BET $\left(\mathbf{m}^{2} \mathbf{~ g}^{-1}\right)$ & Volume of pores $\left(\mathbf{m m}^{\mathbf{3}} \mathbf{~ g}^{-1}\right)$ \\
\hline BL & $24.4 \pm 0.6$ & $161 \pm 1$ \\
BL-POM-3 & $24.8 \pm 0.6$ & $158 \pm 2$ \\
BL-POM $/ \mathrm{H}_{2} \mathrm{O}_{2}-5$ & $22.1 \pm 0.8$ & $139 \pm 2$ \\
\hline
\end{tabular}

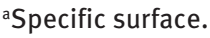

Only the data of the lignin modified with $\mathrm{POM} / \mathrm{H}_{2} \mathrm{O}_{2}$ are slightly lower than those of the reference.

The pore size distribution profiles of modified lignin samples were similar to that for the parent BL (Figure 3); only a slight increase in the mesopore diameters was observed for the sample BL-POM-3. It can be safely

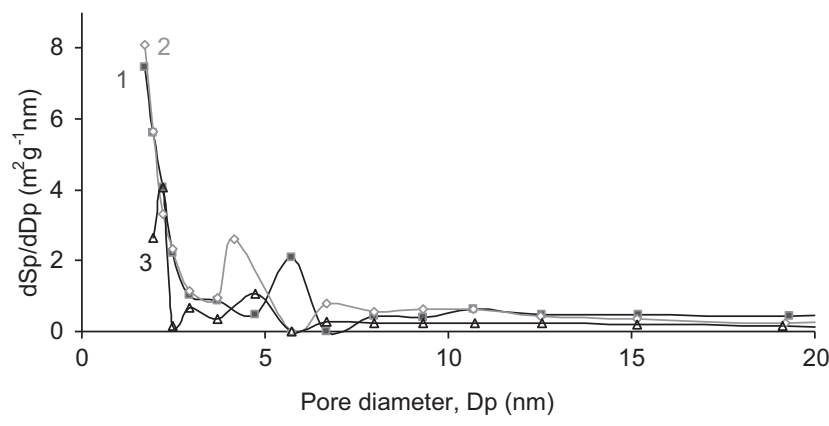

Figure 3 Pore size distribution profiles of $B L$ samples: (1) $B L$, (2) BL-POM-3, and (3) BL-POM- $\mathrm{H}_{2} \mathrm{O}_{2}-5$. concluded that the porous structure of BL remained unaffected in the course of oxidative modifications.

The sorption capacity of the oxidized BLs toward Cd(II) and $\mathrm{Pb}(\mathrm{II})$ was significantly higher than that of the reference BL, as shown by the $b$ values in Table 8 . The sorption of $\mathrm{Cd}$ (II) and $\mathrm{Pb}$ (II) on the BL, BL-POM-3, and BL-POM/ $\mathrm{H}_{2} \mathrm{O}_{2}$ samples corresponds to an L-type isotherm in the Giles classification system for solute adsorption isotherms and the experimental sorption equilibrium data for both metals fit well to the Langmuir model (Faust and Aly 1987):

$$
\frac{C_{e}}{q_{e}}=\frac{1}{b q_{\max }}+\frac{C_{e}}{q_{\max }},
$$

where $q_{\max }$ is the maximal monolayer sorption capacity $\left(\mathrm{mmol} \mathrm{g}^{-1}\right), q_{e}$ is the metal uptake ( $\left.\mathrm{mmol} \mathrm{g}^{-1}\right), C_{e}$ is the metal equilibrium concentration ( $\mathrm{mmol} \mathrm{l}^{-1}$ ), and $b$ is the Langmuir constant characteristic to affinity of sorbent to sorptive (Figure 4).

The values of maximum sorption capacity, $q_{\max }$, calculated for $\mathrm{Cd}$ and $\mathrm{Pb}$ from the Langmuir equation, were significantly higher for the both modified lignins than those for the parent BL (Table 8). The modification with $\mathrm{POM} / \mathrm{H}_{2} \mathrm{O}_{2}$ resulted in more than threefold increased sorption capacity of BL toward Cd (from 125 up to $496 \mu \mathrm{mol} \mathrm{g}^{-1}$ ), whereas for $\mathrm{Pb}$ only twofold increase of $q_{\max }$ (from 370 up to $751 \mu \mathrm{mol} \mathrm{g}$ ) ) was observed. The revealed sorption capacities of BL and its oxidized forms are comparable with or
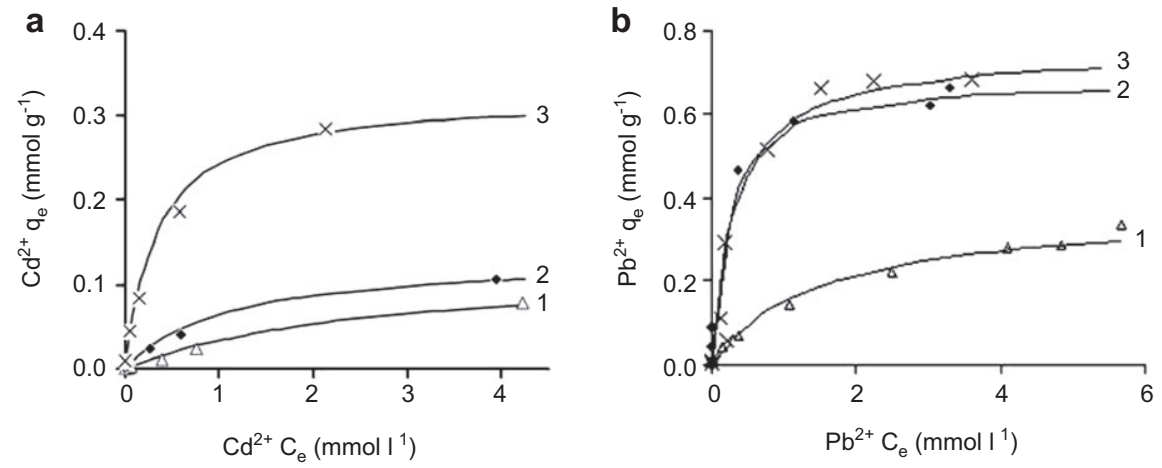

Figure 4 Cadmium (a) and lead (b) adsorption isotherms by BL samples: (1) BL, (2) BL-POM-3, and (3) BL-POM- $\mathrm{H}_{2} \mathrm{O}_{2}-5$. Solid line denotes the adsorption isotherms predicted by the Langmuir model.

Table 8 Langmuir isotherm parameters for $\mathrm{Cd}^{2+}$ and $\mathrm{Pb}^{2+}$ adsorption on $\mathrm{BL}$ samples.

\begin{tabular}{|c|c|c|c|c|c|c|}
\hline \multirow[t]{2}{*}{ Sample } & \multicolumn{3}{|r|}{$\mathrm{Cd}(\mathrm{II})$} & \multicolumn{3}{|r|}{$\mathrm{Pb}(\mathrm{II})$} \\
\hline & $q_{\max }\left(\mathrm{mmol} \mathrm{g}^{-1}\right)$ & $b\left(\mathrm{mmol} \mathrm{l}^{-1}\right)$ & $r$ & $q_{\max }\left(\mathrm{mmol} \mathrm{g}^{-1}\right)$ & $b\left(\mathrm{mmol} \mathrm{l}^{-1}\right)$ & \\
\hline$B \mathrm{~L}$ & $0.13 \pm 0.01$ & $0.44 \pm 0.04$ & 0.999 & $0.37 \pm 0.01$ & $0.92 \pm 0.05$ & 0.987 \\
\hline BL-POM-3 & $0.16 \pm 0.01$ & $0.94 \pm 0.05$ & 0.995 & $0.68 \pm 0.03$ & $4.54 \pm 0.05$ & 0.990 \\
\hline BL-POM- $\mathrm{H}_{2} \mathrm{O}_{2}-5$ & $0.32 \pm 0.03$ & $0.98 \pm 0.05$ & 0.989 & $0.75 \pm 0.03$ & $3.09 \pm 0.05$ & 0.992 \\
\hline
\end{tabular}


higher than that reported in the literature for other lignocellulosic materials. For example, the range of maximum sorption capacity toward Cd between 8 and $28 \mu \mathrm{mol} \mathrm{g}^{-1}$ was reported for kraft and organosolv lignins from softwoods and hardwoods (Harmita et al. 2009). For $\mathrm{Pb}$ removal from aqueous solutions, the values of $q_{\text {max }}$ from 2 up to 900 $\mu \mathrm{mol} \mathrm{g}{ }^{-1}$ were achieved by modified lignocellulosics (Wan Ngah and Hanafiah 2008).

The increased values of the Langmuir constant $b$ indicated enhancement of modified BL affinity toward heavy metal cations. Probably, the formation of new $\mathrm{COOH}$ groups after oxidative modification are potential sites for coordinative linkages with metals.

\section{Conclusion}

The yield of the oxidized products was $88 \%$ in experiments with the cooxidants $\mathrm{O}_{2}$ or $\mathrm{H}_{2} \mathrm{O}_{2}$. The modified lignins revealed a notable increase in the number of carboxyl and aliphatic hydroxyl groups after the oxidation by $\mathrm{POM} / \mathrm{O}_{2}$ and $\mathrm{POM} / \mathrm{H}_{2} \mathrm{O}_{2}$. The introduction of conjugated carbonyl groups was typical only for $\mathrm{POM} / \mathrm{H}_{2} \mathrm{O}_{2}$. The solubility of the oxidized lignin decreased due to condensation reactions. The sorption ability toward $\mathrm{Cd}$ and $\mathrm{Pb}$ cations was the best by application of the system $\mathrm{POM} / \mathrm{H}_{2} \mathrm{O}_{2}$. This can be explained by the highest amounts of primary $\mathrm{COOH}$ groups formed, which increase the sites for coordinative linkages to metals.

Acknowledgements: The financial support from the $7^{\text {th }} \mathrm{FP}$ project BIOCORE, Contract FP7-241566 and Latvian budget, Contract ES12-13 and LZP grants 09.1547 and 564/2012 are gratefully acknowledged.

Received November 1, 2012; accepted March 1, 2013; previously published online May 11, 2013

\section{References}

Abad, S., Santos, V., Parajó, J.C. (2002) Formic acid-peroxyformic acid pulping of aspen wood: an optimization study. Holzforschung 54:544-552.

Babel, S., Kurniawan, T.A. (2003) Low-cost adsorbents for heavy metals uptake from contaminated water: a review. J. Hazard. Mater. B 97:219-243.

Basso, M.C., Cerrella, E.G., Cukierman, A.L. (2002) Lignocellulosic materials as potential biosorbents of trace toxic metals from wastewater. Ind. Eng. Chem. Res. 41:3580-3585.

Boving, T.B., Zhang, W. (2004) Removal of aqueous-phase polynuclear aromatic hydrocarbons using aspen wood fibers. Chemosphere 54:831-839.

Chen, C.L., Robert, D. (1988) Characterization of lignin by ${ }^{1} \mathrm{H}$ and ${ }^{13} \mathrm{C}$ NMR spectroscopy. Methods Enzymol. 161:137-158.

Claus, I., Kordsachia, O., Schröder, N., Karstens, T. (2004) Monoethanolamine (MEA) pulping of beech and spruce wood for production of dissolving pulp. Holzforschung 58:573-580.

Crist, R.H., Martin, R.J., Crist, D.R. (2005) Use a novel formulation of kraft lignin for toxic metal removal from process waters. Separation Sci. Technol. 39:1535-1545.

Del Rio, J.C., Rencoret, J., Prinsen, P., Martínez, Á.T., Ralph, J., Ana Gutiérrez, A. (2012) Structural characterization of wheat straw lignin as revealed by analytical pyrolysis, 2D-NMR, and reductive cleavage methods. J. Agric. Food Chem. 60:5922-5935.

Delmas, M. (2008) Vegetal refining and agrochemistry. Chem. Eng. Technol. 31:792-797.

Delmas, G.H., Benjelloun-Mlayah, B., Le Bigot, Y., Delmas, M. (2011) Functionality of wheat straw lignin extracted in organic acid media. J. Appl. Polym. Sci. 121:491-501.

Demirbas, A. (2004) Adsorption of lead and cadmium ions in aqueous solutions onto modified lignin from alkali glycerol delignication. J. Hazard. Mater. B 109:221-226.
Dizhbite, T., Zakis, G., Kizima, A., Lazareva, E., Rossinskaya, G., Jurkjane, V., Telysheva, G., Viesturs, U. (1999) Lignin a useful bioresource for the production of sorption-active materials. Bioresour. Technol. 67:221-228.

Dizhbite, T., Telysheva, G., Jashina, L., Dobele, G., Volperts, A., Andersone, A., Ponomarenko, J., Mironova-Ulmane, N., Sidos, I. (2011) Lignin oxidation using heteropolyanions of the Keggin's type as catalysts. International conference FM\&NT'2011, Riga, April 5-8, Book of Abstracts, p. 261.

Dos Santos, D., Rudnitskaya, A., Evtuguin, D. (2012) Modified kraft lignin for bioremediation applications. J. Environ. Sci. Health A Tox. Hazard. Subst. Environ. Eng. 47:298-307.

Evtuguin, D.V., Pascoal Neto, C., Carapuça, H., Soares, J. (2000) Lignin degradation in oxygen delignification catlyased by $\left[\mathrm{PMO}_{7} \mathrm{~V}_{5} \mathrm{O}_{40}\right]^{8}$ polyanions. Part II. Study on lignin monomeric model compounds. Holzforschung 54:511-518.

Evtuguin, D.V., Rocha, G., Goodfellow, B.J. (2009) Detection of muconic acid type structures in oxidized lignin employing 2D NMR spectroscopy. Holzforschung 63:675-680.

Faix, O. (1991a) Classification of lignin from different botanical origins by FT-IR spectroscopy. Holzforschung 45:21-27.

Faix, O. (1991b) Condensation indices of lignins determined by FTIR-spectroscopy. Holz Roh Werkst. 49:356.

Faust, S.D., Aly, O.M. Adsorption Processes for Water Treatment. Butterworth Scientific Ltd., Guidford, 1987.

Fengel, D., Wegener, G. Wood - Chemistry, Ultrastructure, Reactions. De Gruyter, Berlin, 1989, p. 613.

Gaspar, A.R., Evtuguin, D.V., Pascoal Neto, C. (2004) Polyoxometalate catalyzed oxygen delignification of kraft pulp: a pilot-plant experience. Ind. Eng. Chem. Res. 43:7754-7761.

Gregg, S.J., Sing, K.S. Adsorption, Surface Area and Porosity. Academic Press, Inc., London, 1982. 
Guo, X., Zhang, S., Shan, X. (2008) Adsorption of metal ions on lignin. J. Hazard. Mater. 151:134-142.

Guo, S., Zhong, L., Hui, L.-F., Si, C.-L., Pang, J.-J. (2011) Application of polyoxometalate in hydrogen peroxide bleaching under acidic conditions. Bioresources 6:1251-1261.

Gütsch, J.S., Sixta, H. (2011) Purification of Eucalyptus globulus water prehydrolyzates using the HiTAC process (high-temperature adsorption on activated charcoal). Holzforschung 65:511-518.

Harmita, H., Karthikeyan, K.G., Pan, X. (2009) Copper and cadmium sorption onto kraft and organosolv lignins. Bioresour. Technol. 100:6183-6191.

Hawkes, G.E., Smith, C.Z., Utley, J.H.P., Vargas, R.R., Viertler, H.A. (1993) Comparison of solution and solid-state 13C NMR spectra of lignins and lignin model compounds. Holzforschung 47:302-312.

Hörhammer, H., Walton, S., van Heiningen, A. (2011) A larch based biorefinery: pre-extraction and extract fermentation to lactic acid. Holzforschung 65:491-496.

lakovlev, M., Pääkkönen, T., van Heiningen, A. (2009) Kinetics of $\mathrm{SO}_{2}$-ethanol-water pulping of spruce. 10th EWLP, Stockholm, Sweden, August 25-28, 2008.

Jiménez, L., de la Torre, M.J., Maestre, F., Ferrer, J.L., Pérez, I. (1998) Delignification of wheat straw by use of low-molecular-weight organic acids. Holzforschung 52:191-196.

Jiménez, L., Rodríguez, A., Díaz, M.J., López, F., Ariza, J. (2004) Organosolv pulping of olive tree trimmings by use of ethylene glycol/soda/water mixtures. Holzforschung 58:122-128.

Kubelka, V., Francis, R.C., Dence, C.W. (1992) Delignification with acidic hydrogen peroxide activated by molybdate. J. Pulp Pap. Sci. 18:108-111.

Lam, H.Q., Le Bigot, Y., Delmas, M., Avignon, G. (2001) A new procedure for the destructuring of vegetable matter at atmospheric pressure by a catalyst/solvent system of formic acid/acetic acid. Applied to the pulping of triticale straw. Ind. Crops Prod. 14:139-144.

Lehnen, R., Saake, B., Nimz, H.H. (2002) Impact of pulping conditions on FORMACELL aspen lignin: investigation of methoxyl and ester groups, carbohydrates, molar mass and glass transition temperatures. Holzforschung 56:498-506.

Lin, S.Y., Dence, C.W. (1992) General structural features of lignin. In: Methods in Lignin Chemistry. Eds. Lin, S.Y., Dence C.W. Springer, Berlin, pp. 3-23.

McBeath, A.V., Smernik, R.J., Schneider, M.P.W., Schmidt, M.W.I., Plant, E.L. (2011) Determination of the aromaticity and the degree of aromatic condensation of a thermosequence of wood charcoal using NMR. Org. Geochem. 42:1194-1202.

Mohan, D., Pittman Jr., C.U., Steele, F.H. (2006) Single, binary and multi-component adsorption of copper and cadmium from aqueous solutions on Kraft lignin - a biosorbent. J. Colloid Interf. Sci. 297:489-504.

Ohra-aho, T., Tenkanen, M., Tamminen, T. (2005) Direct analysis of lignin and lignin-like components from softwood kraft pulp by Py-GC/MS techniques. J. Anal. Appl. Pyrol. 74:123-128.

Rabelo, M.S., Colodette, J.L., Sacon, V.M., Silva, M.R., Azevedo, M.A.B. (2008) Molybdenum catalyzed acid peroxide bleaching of Eucalyptus kraft pulp. Bioresources 3:881-897.
Rachkova, N.G., Shuktomova, I.I., Taskaev, A.I. (2006) Sorption of uranium, radium, and thorium from saline solutions on hydrolyzed wood lignin. Russ. J. Appl. Chem. 79:715-721.

Saake, B., Lehnen, R., Schmekal, E., Neubauer, A., Nimz, H.H. (1998) Bleaching of Formacell pulp from aspen wood with ozone and peracetic acid in organic solvents. Holzforschung 52:643-650.

Sarkanen, K.V., Ludwig, C.H. (Eds). Lignins - Occurence, Formation, Structure and Reactions. Wiley-Interscience, New York, 1971, p. 916.

Schütt, F., Puls, J., Saake, B. (2011) Optimization of steam pretreatment conditions for enzymatic hydrolysis of poplar wood. Holzforschung 65:453-459.

Sing, K.S.W., Everett, D.H., Haul, R.A.W., Moscou, L., Pierotti, R.A., Rouquerol, J., Siemieniewska, T. (1985) Reporting physisorption data for gas/solid systems with special reference to the determination of surface area and porosity. Pure Appl. Chem. 57:603-619.

Suhas, Carrott, P.J.M., Ribeiro Carrott, M.M.L. (2007) Lignin - from natural adsorbent to activated carbon: a review. Bioresour. Technol. 98:2301-2312.

Tamminen, T., Liitiä, T., Ohra, T., Hortling, B. (2004) Do we need to isolate pulp residual lignin forits structural characterization? In: Proceedings of 8th EWLP on Utilization of Lignocellulosics and By-products of Pulping, Riga, Latvia, pp. 37-40.

Taube, F., Schukarve, A., Li, J., Gellerstedt, G., Agnemo, R. (2008) Peroxomolybdate catalysts in pulp hydrogen peroxide bleaching: improvement inhexeneuronic acid removal and delignification. TAPPI J. 7:8-14.

Telysheva, G., Dizhbite, T., Lebedeva, G., Zaimenko, N., Popovs, S. (2006) Regulation of lignocellulose materials sorption properties by modification for environmental application. In: Combined and Hybrid Adsorbents. Fundamentals and Applications. Eds. Loureiro, J.M., Kartel, M. Springer, Netherlands. pp. 271-276.

Testova, L., Chong, S.-L., Tenkanen, M., Sixta, H. (2011) Autohydrolysis of birch wood. Holzforschung 65:535-542.

Wan Ngah, W.S., Hanafiah, M.A.K.M. (2008) Removal of heavy metal ions from wastewater by chemically modified plant wastes as adsorbents: a review. Bioresour. Technol. 99: 3935-3948.

Weinstock, I., Atalla, R., Reiner, R., Houtman, C., Hill, C. (1998) Selective transition-metal catalysis of oxygen delignification using water-soluble salts of polyoxometalate (POM) anions. Part I. Chemical principles and process concepts. Holzforschung 52:304-310.

Xiao, L.P., Shi, Z.-J., Xu, F., Sun, R.C. (2012) Characterization of MWLs from Tamarix ramosissima isolated before and after hydrothermal treatment by spectroscopical and wet chemical methods. Holzforschung 66:295-302.

Yawalata, D., Paszner, L. (2006) Characteristics of NAEM salt-catalyzed alcohol organosolv pulping as a biorefinery. Holzforschung 60:239-244.

Zakis, G.F. Functional Analysis of Lignins and Their Derivatives. TAPPI Press, Atlanta, 1994. 